See Article page $\mathrm{XXX}$.

\section{Commentary: How radical is radial? A tale of 2 grafts}

\author{
Jeremy Y. Levett, ${ }^{\mathrm{a}}$ Derrick Y. Tam, MD, $\mathrm{PhD},{ }^{\mathrm{b}}$ and \\ Stephen E. Fremes, MD, MSc ${ }^{b}$
}

\begin{abstract}
Although coronary artery bypass grafting (CABG) surgery remains the optimal revascularization strategy for patients with severe triple-vessel coronary artery disease, optimal conduit selection remains controversial. The 2018 European Society of Cardiology/European Association for Cardio-Thoracic Surgery guidelines on myocardial revascularization have endorsed, with a Class 1B recommendation, the use of the radial artery over the saphenous vein in patients with a high-grade coronary artery stenosis, ${ }^{1}$ largely on the basis of an individual patient-level meta-analysis of randomized controlled trials (RCTs), and prospective studies favoring radial artery grafting over saphenous vein grafting. ${ }^{2-6}$ Furthermore, in patients not at high risk of sternal wound infections, the use of bilateral internal thoracic artery (BITA) grafting has been issued a Class $2 \mathrm{~A}$ recommendation in the interest of maximizing longterm graft patency (Figure 1). ${ }^{1}$ However, limited robust data are known about the role of the radial artery as a third arterial graft.
\end{abstract}

In this issue of the Journal, Formica and colleagues ${ }^{7}$ elucidate the long-term survival influence of adding the radial artery to BITA grafting in a systematic review and meta-analysis. Among 2500 patients from 6 propensity score-matched studies, at a mean follow-up time ranging between 7.5 and 12 years, BITA and radial artery grafting, compared with BITA and saphenous vein grafting, was

\footnotetext{
From the a Faculty of Medicine and Health Sciences, McGill University, Montreal, Québec, Canada; and ${ }^{\mathrm{b}}$ Division of Cardiac Surgery, Department of Surgery, Schulich Heart Centre, Sunnybrook Health Sciences Centre, University of Toronto, Toronto, Ontario, Canada.

Disclosures: The authors reported no conflicts of interest.

The Journal policy requires editors and reviewers to disclose conflicts of interest and to decline handling or reviewing manuscripts for which they may have a conflict of interest. The editors and reviewers of this article have no conflicts of interest.

Received for publication Aug 6, 2021; revisions received Aug 6, 2021; accepted for publication Aug 9, 2021.

Address for reprints: Derrick Y. Tam, MD, PhD, Division of Cardiac Surgery, Department of Surgery, Schulich Heart Centre, Sunnybrook Health Sciences Centre, University of Toronto, 2075 Bayview Ave, Toronto, Ontario M4N 3M5, Canada (E-mail: derrick.tam@mail.utoronto.ca).

J Thorac Cardiovasc Surg 2021; $\mathbf{\square}: 1-2$

0022-5223/ $\$ 36.00$

Copyright (c) 2021 by The American Association for Thoracic Surgery

https://doi.org/10.1016/j.jtcvs.2021.08.018
}

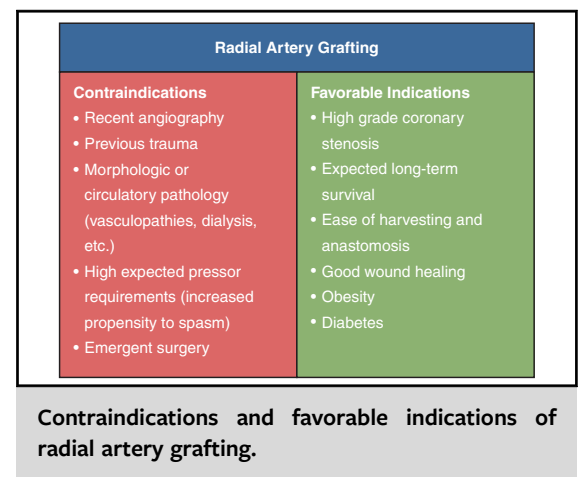

CENTRAL MESSAGE

In a meta-analysis of 2500 patients, bilateral internal-thoracicartery (BITA) and radial-artery grafting, versus BITA and saphenous-vein grafting, was associated with decreased longterm mortality.

associated with significantly decreased long-term mortality (hazard ratio, $0.71 ; 95 \%$ confidence interval $[\mathrm{CI}], 0.50$ 0.91). This benefit was achieved in patients with excellent long-term survival given that all patients had BITA, likely to the 2 most important targets. The survival rate for BITA and radial artery grafting versus BITA and saphenous vein grafting at 5, 10, and 15 years was $96.2 \%(95 \% \mathrm{CI}$, 94.9\%-97.1\%) versus $94.8 \%$ (95\% CI, $93.3 \%-95.9 \%$ ), $88.9 \%$ (95\% CI, 86.9\%-90.7\%) versus $87.4 \%$ (95\% CI, $85.1 \%-89.3 \%$ ), and $83 \%(95 \%$ CI, $79.9 \%-85.6 \%$ ) versus $77.9 \%$ (95\% CI, 74.4\%-81\%), respectively. Importantly, there was no signal of significant early mortality occurring within 30 days or during index hospitalization (odds ratio, 0.90 ; 95\% CI, 0.36-2.28). As well, meta-regression analyses demonstrated that the primary end point was not influenced by any major patient baseline characteristics.

The authors should be commended for undertaking a thorough meta-analysis with important and meaningful clinical implications. Although there is reason for cautious optimism that radial artery versus saphenous vein grafting in addition to BITA grafting is associated with superior long-term survival, these findings must be interpreted carefully. First, the majority of patients included in this metaanalysis were younger than age 70 years, a relatively young and healthy population that theoretically should benefit the most from a third arterial graft. Thus, whether these findings 


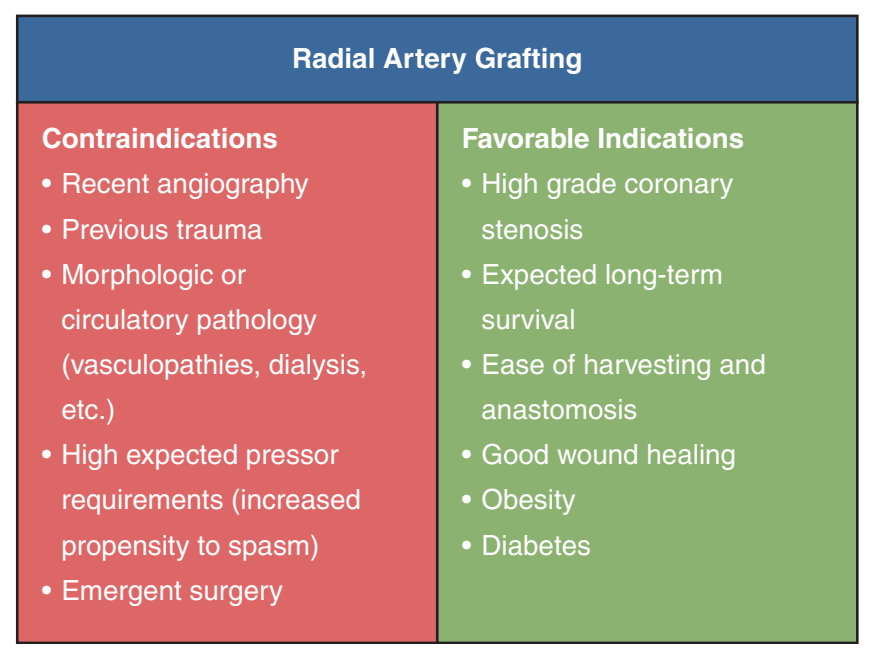

FIGURE 1. Contraindications and favorable indications of radial artery grafting.

would apply to older patients remains uncertain. In a secondary analysis of 10-year data from the Arterial Revascularization Trial, subgroup analyses restricted to patients between ages 50 to 70 years demonstrated that BITA grafting had a significantly lower incidence in major adverse events (all-cause mortality, myocardial infarction, or stroke) when compared with single ITA (SITA) grafting. ${ }^{8}$ However, no overall effect of age on the treatment effect of BITA versus SITA grafting was observed. Second, a limitation of pooling observational studies is that the findings may be subject to significant treatment allocation bias, or confounding by indication (or contraindication). Surgeons are inherently guided by the baseline clinical status, surgical risk, and cardiovascular anatomy of their patients in determining surgical approaches. Therefore, despite the appropriate attempts of included studies to propensity score match patients with similar characteristics, residual bias is likely given the presence of unmeasured and unknown confounders, such as target vessel stenosis severity and myocardial territory, which greatly influence a surgeon's decision. Finally, authors elected to only include propensity score-matched studies in their analysis and excluded those that may have adjusted for confounding by other means. By restricting the systematic review and meta-analysis to propensity score-matched studies, the authors may have excluded relevant multivariable regression or inverse propensity score weighting-adjusted studies. ${ }^{9-11}$

Long-term survival outcomes of CABG surgery are largely predicated by the completeness of revascularization and the durable patency of grafts, which may be influenced by conduit selection. The elasticity of arterial grafts, coupled with their inherent propensity to minimize intimal and medial hyperplasia, which in vein grafts would otherwise result in atherothrombosis and a reduction of patency, has long served as premises that they are the optimal conduit candidates for a complete and long-term revascularization. Previous large observational studies and meta-analyses of propensity score-matched studies have supported this hypothesis, and are consistent with the findings of this meta-analysis. ${ }^{12-14}$ In fact, 1 large propensity score-matched analysis found the use of saphenous vein grafts to be independently and incrementally associated with reduced survival after CABG surgery. ${ }^{15}$ However, these findings have yet to be confirmed by a large RCT with sufficient long-term follow-up, which may be why total arterial revascularization or the use of multiple arterial grafts, in patients with triple-vessel coronary artery disease, is far from routine surgical practice. In the largest trial of BITA versus SITA grafting, there was no significant difference in mortality or the rates of major adverse events at 10-year follow-up. ${ }^{16}$ While we await RCTs with sufficient long-term data, the known and potential benefits of radial artery grafting in addition to BITA grafting warrants further consideration in patients with a very long anticipated life expectancy, especially because it appears to outweigh any known and potential risks. As CABG surgery's journey continues to unfold, so too will the tale of the arterial and venous grafts that perfuse it.

\section{References}

1. Neumann FJ, Sousa-Uva M, Ahlsson A, Alfonso F, Banning AP, Benedetto U, et al. 2018 ESC/EACTS Guidelines on myocardial revascularization. Eur Heart J. 2019;40:87-165.

2. Gaudino M, Benedetto U, Fremes S, Biondi-Zoccai G, Sedrakyan A, Puskas JD, et al. Radial-artery or saphenous-vein grafts in coronary-artery bypass surgery. $N$ Engl J Med. 2018;378:2069-77.

3. Desai ND, Cohen EA, Naylor CD, Fremes SE. A randomized comparison of radial-artery and saphenous-vein coronary bypass grafts. N Engl J Med. 2004; 351:2302-9.

4. Taggart DP, Altman DG, Flather M, Gerry S, Gray A, Lees B, et al. Associations between adding a radial artery graft to single and bilateral internal thoracic artery grafts and outcomes: insights from the Arterial Revascularization Trial. Circulation. 2017; 136:454-63.

5. Yamasaki M, Deb S, Tsubota H, Moussa F, Kiss A, Cohen EA, et al. Comparison of radial artery and saphenous vein graft stenosis more than 5 years after coronary artery bypass grafting. Ann Thorac Surg. 2016;102:712-9. 
6. Gaudino M, Tondi P, Benedetto U, Milazzo V, Flore R, Glieca F, et al. Radial artery as a coronary artery bypass conduit: 20-year results. J Am Coll Cardiol. 2016;68:603-10.

7. Formica F, Maestri F, D’Alessandro S, Di Mauro M, Singh G, Gallingani A, et al. Survival impact of radial artery usage in addition to bilateral internal thoracic arterial grafting: a meta-analysis. J Thorac Cardiovasc Surg. 2021;XX: XX-XXX.

8. Gaudino M, Di Franco A, Flather M, Gerry S, Bagiella E, Gray A, et al. Association of age with 10-year outcomes after coronary surgery in the Arterial Revascularization Trial. J Am Coll Cardiol. 2021;77:18-26.

9. Tam DY, Vo TX, Wijeysundera HC, Ko DT, Rocha RV, Friedrich J, et al. Transcatheter vs surgical aortic valve replacement for aortic stenosis in low-intermediate risk patients: a meta-analysis. Can J Cardiol. 2017;33: 1171-9.

10. Parmar MK, Torri V, Stewart L. Extracting summary statistics to perform metaanalyses of the published literature for survival endpoints. Stat Med. 1998;17: 2815-34.
11. Tierney JF, Stewart LA, Ghersi D, Burdett S, Sydes MR. Practical methods for incorporating summary time-to-event data into meta-analysis. Trials. 2007;8:16

12. Gaudino M, Puskas JD, Di Franco A, Ohmes LB, Iannaccone M, Barbero U, et al Three arterial grafts improve late survival: a meta-analysis of propensitymatched studies. Circulation. 2017;135:1036-44.

13. Yanagawa B, Verma S, Mazine A, Tam DY, Jüni P, Puskas JD, et al. Impact of total arterial revascularization on long term survival: a systematic review and meta-analysis of 130,305 patients. Int J Cardiol. 2017;233:29-36.

14. Rocha RV, Tam DY, Karkhanis R, Wang X, Austin PC, Ko DT, et al. Long-term outcomes associated with total arterial revascularization vs non-total arterial revascularization. JAMA Cardiol. 2020;5:507-14.

15. Royse A, Pawanis Z, Canty D, Ou-Young J, Eccleston D, Ajani A, et al. The effect on survival from the use of a saphenous vein graft during coronary bypass surgery: a large cohort study. Eur J Cardiothorac Surg. 2018;54:1093-100.

16. Taggart DP, Benedetto U, Gerry S, Altman DG, Gray AM, Lees B, et al. Bilatera versus single internal-thoracic-artery grafts at 10 years. N Engl J Med. 2019;380: 437-46. 